\title{
Heterotopic ossification in non-traumatic myelopathies
}

\author{
AB Taly ${ }^{1}$, KPS Nair ${ }^{1}$, M Veerendra Kumar ${ }^{1}$, PN Jayakumar ${ }^{2}$, MK Vasudev ${ }^{2}$, D Ravishankar ${ }^{3}$, PL Kalaivant ${ }^{1}$ \\ BS Padankatty ${ }^{1}$ and $T$ Murali ${ }^{1}$ \\ Departments of ${ }^{1}$ Neurology, Psychiatric and Neurological Rehabilitation, ${ }^{2}$ Neuroradiology, ${ }^{3}$ Consultant \\ Orthopaedician, National Institute of Mental Health and Neuro Sciences (NIMHANS) Bangalore, India
}

\begin{abstract}
Heterotopic ossification (HO) is an important complication of spinal cord and brain injuries but is rarely reported among patients with non-traumatic myelopathies. In a prospective study on medical problems seven $(6.04 \%)$ among the 114 subjects with non-traumatic myelopathies had heterotopic ossification. All of them had involvement of hip joints. The co-morbid conditions were: urinary tract infection, seven; spasticity, three; pressure sores, five; and deep venous thrombosis, one. The initial diagnosis was often other than heterotopic ossification. Erythrocyte sedimentation rate and serum alkaline phosphatase levels were elevated in all subjects. Following rest and non-steroidal anti-inflammatory drugs, the range of motion improved in two patients. Heterotopic ossification can occur in patients with non-traumatic myelopathies and has risk factors and clinical features similar to patients with traumatic spinal cord injury. A high index of suspicion about this complication is necessary for early diagnosis and prompt intervention.
\end{abstract}

Keywords: non-traumatic myelopathies; heterotopic; ossification; spinal cord injury; paraplegia

\begin{abstract}
Introduction
Heterotopic ossification (HO) is an important cause of disability following traumatic brain and spinal cord injuries (SCI). It is only rarely reported after nontraumatic neurological disorders. ${ }^{1}$ Several factors, both hereditary and acquired, have been implicated in the pathogenesis of HO. However, their exact role is far from clear. This report describes seven patients with non-traumatic myelopathies (NTM) with $\mathrm{HO}$ seen at the Neurological Rehabilitation unit, National Institute of Mental Health And Neurosciences (NIMHANS), Bangalore, India.
\end{abstract}

\section{Patients and Methods}

A prospective study of medical problems among patients admitted for in-patient Nerological rehabilitation was conducted between 1.7.1992 and 31.8.1995 at the National Institute of Mental Health and Neuro Sciences (NIMHANS), Bangalore, India. ${ }^{2}$ From this study, subjects with clinical and radiological evidence of $\mathrm{HO}$ were selected. A detailed history regarding trauma, surgery, onset and evolution of neurological deficits, the interval between the onset of neurological deficits and symptoms suggesting HO was obtained. All patients were subjected to physical and neurological examination. The level and the completeness of the lesion and etiology of NTM were assessed. The

Correspondence: AB Taly, Additional Professor, Department of Neurology, NIMHANS, Hosur Road, Bangalore-560 029, India
American Spinal Injury Association (ASIA) impairment scale was used to describe the completeness of the spinal cord lesion. ${ }^{3}$ Risk factors for HO like deep venous thrombosis (DVT), spasticity, pressure sore and urinary tract infection were noted. The clinical features studied were range of motion (ROM), fever, erythema of the affected limb, localized soft tissue swelling, and warmth. The joints affected and initial diagnosis were also noted. The details of laboratory investigations including Erythrocyte sedimentation rate (ESR), serum alkaline phosphatase (SAP) levels and the radiological investigations were reviewed.

\section{Results}

Among the 114 patients with NTM, admitted to the Neurological rehabilitation unit, seven patients $(6.04 \%)$ had clinical and radiological evidence of HO. The etiology of NTM, clinical features, level of the lesion and interval between onset of disease and detection of HO are shown in Table 1. There was no history of trauma but two patients underwent surgery for Pott's spine. The lesion was complete (ASIA grade-A) in six patients and incomplete (ASIA grade-B) in one. The concomitant risk factors were: DVT, one; spasticity, three; pressure sores, five and urinary tract infection, seven. All the seven subjects had involvement of hip joints only. In three patients with acute onset of pain and swelling of legs a diagnosis of DVT was considered. The initial X-rays were normal. All of them were advised rest and received NSAID and 
heparin. Radiological evaluation repeated after four to 8 weeks revealed HO. One patient while on heparin developed pain and swelling of the thigh after vigorous physiotherapy. The initial diagnosis was soft tissue haematoma. X-rays of the hip joint and thigh were normal. Heparin was stopped and the patient was put on NSAIDs. X-rays done 3 months later showed HO. One patient had decreased passive ROM of the hip joint 8 months after transverse myelitis and in two other patients with pain, swelling and decreased ROM, $\mathrm{HO}$ was considered clinically and confirmed radiologically. The ESR and SAP levels were elevated in all (Table 1). Serial estimation of SAP was done in four subjects. The SAP levels continued to rise for 7 to 17 weeks after the onset of HO. The peak levels were noted between 8 and 17 weeks. The location of $\mathrm{HO}$ was anteromedial in five and perifemoral and anterolateral in one each. Computerized tomographic (CT) scan, done in two subjects, revealed calcification around the hip joints.

Three patients were treated with indomethacin. Two patients received diclofenac sodium and two others ibuprofen. Range of motion exercises were stopped until all signs of inflammation subsided and ESR and alkaline phosphatase returned to normal levels. Five patients did not show any improvement in passive ROM of affected joints. All five of them had persistent $\mathrm{HO}$ in X-rays done after 3-5 months. Range of motion improved in two subjects, however none had radiological resolution.

\section{Discussion}

The incidence of HO in SCI varies from $16 \%$ to $53 \%{ }^{4}$ However, its incidence in NTM is not known. In the present series seven of the 114 subjects $(6.04 \%)$ with NTM developed this complication. $\mathrm{HO}$ is often regarded as a complication of traumatic brain and spinal cord injuries. ${ }^{1,5,6}$ However, other than two patients who underwent surgery for Pott's spine, none had overt trauma. HO is reported to be more common among patients with cervical cord injury but none of the patients in the present series had cervical myelopathy. Bravo-Payno et al also did not find any significant association between level of SCI and $\mathrm{HO}^{7}$ Complete transverse SCI was more commonly associated with HO than incomplete lesions. ${ }^{7}$ Among seven patients with NTM six had clinically complete spinal cord transection (ASIA grade-A). HO usually involves hip, knee and elbow joints of paretic limbs. In the current study all the seven subjects had $\mathrm{HO}$ around the hip joints of paretic limbs. The onset of HO after SCI ranges from 4 to 12 weeks. ${ }^{5}$ In the present series $\mathrm{HO}$ was detected between 4 and 32 weeks after onset of the symptoms (Table 1). Early manifestations of HO may mimic DVT, arthritis, infection and tumour. In the current series, initially the diagnosis of $\mathrm{HO}$ was considered in only two subjects. The most common symptom of $\mathrm{HO}$, pain, ${ }^{5}$ was noted in four patients. However absence of pain in others could be due to severe sensory deficit. Limitation of range of motion, the most common sign, ${ }^{5}$ was present in all.

Plain X-rays are useful in the diagnosis and monitoring the progression of $\mathrm{HO},{ }^{1}$ but may be negative during the early stages. In the present series $\mathrm{X}$-rays were initially normal in four patients. In patients with SCI, HO usually occurs along the anteromedial plane of the hip joint. ${ }^{5}$ Five of the subjects with NTM also had HO at this site. The role of $\mathrm{CT}$ in the diagnosis of $\mathrm{HO}$ has not been extensively studied. HO may involve soft tissue structures like blood vessels and nerves. ${ }^{4,8} \mathrm{CT}$ is more sensitive than X-rays for early detection of calcification and delineation of bone from soft tissues. In two patients CT helped in detecting $\mathrm{HO}$ and the extent of soft tissue involvement. The gold standard for the

Table 1 Clinical features and laboratory investigations of patients with non-traumatic myelopathies and heterotopic ossification

\begin{tabular}{|c|c|c|c|c|c|c|c|c|c|}
\hline $\begin{array}{l}\text { Sl. } \\
\text { No. }\end{array}$ & $\begin{array}{c}\text { Age } \\
\text { (years) }\end{array}$ & Sex & Aetiology & $\begin{array}{l}\text { Deficit } \\
\text { level }\end{array}$ & $\begin{array}{l}\text { Interval } \\
\text { in weeks }\end{array}$ & Clinical features & $\begin{array}{l}\text { Initial } \\
\text { diagnosis }\end{array}$ & $\begin{array}{c}E S R \\
m m / h\end{array}$ & $\begin{array}{l}S A P^{*} \\
I U / L\end{array}$ \\
\hline 1 & 67 & M & TB spine & $\mathrm{T} 10-\mathrm{T} 11$ & 6 & $\begin{array}{l}\text { Pain, reduced } \\
\text { ROM, swelling }\end{array}$ & DVT & 38 & 120 \\
\hline 2 & 47 & $\mathrm{~F}$ & TB spine & $\mathrm{T} 4-\mathrm{T} 5$ & 12 & $\begin{array}{l}\text { Pain, swelling } \\
\text { reduced ROM }\end{array}$ & Haematoma & 58 & 186 \\
\hline 3 & 22 & $\mathrm{~F}$ & $\mathrm{TM}$ & $\mathrm{T} 5-\mathrm{T} 6$ & 7 & $\begin{array}{c}\text { Swelling, reduced } \\
\text { ROM }\end{array}$ & DVT & 50 & 229 \\
\hline 4 & 16 & $\mathrm{~F}$ & $\begin{array}{c}\text { TB } \\
\text { arachnoiditis }\end{array}$ & T6 & 4 & $\begin{array}{l}\text { Pain, } \\
\text { reduced ROM }\end{array}$ & $\mathrm{HO}$ & 30 & 375 \\
\hline 5 & 16 & $\mathrm{~F}$ & $\mathrm{TM}$ & $\mathrm{T} 4-\mathrm{T} 5$ & 12 & $\begin{array}{l}\text { Swelling, erythema, } \\
\text { reduced ROM }\end{array}$ & DVT & 88 & 905 \\
\hline 6 & 29 & M & $\begin{array}{c}\text { TB } \\
\text { arachnoiditis }\end{array}$ & $\mathrm{T}-5$ & 28 & $\begin{array}{l}\text { Pain, swelling, } \\
\text { reduced ROM }\end{array}$ & $\mathrm{HO}$ & 75 & 797 \\
\hline 7 & 13 & $\mathrm{~F}$ & TM & $\mathrm{T} 4$ & 32 & Reduced ROM & $\mathrm{HO}$ & 110 & 250 \\
\hline
\end{tabular}

$\mathrm{TB}=$ tuberculosis; $\mathrm{TM}=$ transverse myelitis; $\mathrm{T}=$ thoracic; $\mathrm{ROM}=$ range of motion; $\mathrm{ESR}=$ erythrocyte sedimentation rate; $\mathrm{mm}$ first hour = millimeters per hour; $\mathrm{SAP}=$ serum alkaline phosphatase; $\mathrm{IU} / \mathrm{L}=$ international units per liter; $\mathrm{M}=\mathrm{male} ; \mathrm{F}=\mathrm{female}$; $\mathrm{DVT}=$ deep venous thrombosis; $\mathrm{HO}=$ heterotopic ossification; *Normal $30-110 \mathrm{IU} / \mathrm{L}$ 
diagnosis of $\mathrm{HO}$ is three phase bone scan. ${ }^{1}$ The pathogenesis of HO includes early vascularity and the development of nonossified osteoid matrix before actual calcification. As X-rays show only the final calcified stage, three phase bone scan is required for early diagnosis. The drawbacks of this test are cost, radiation and lack of availability. This test was not done in any of the patients in the current study. Hence patients with early stages of $\mathrm{HO}$ could have been excluded from this study, accounting for the lower incidence in this series $(6.04 \%)$ compared to other reports $(16 \%-53 \%){ }^{4}$ Ultrasonography is useful in differentiating $\mathrm{HO}$ from primary bone tumours, haematomas and abscess ${ }^{6,9}$ but was not performed in this study.

Co-morbid conditions associated with $\mathrm{HO}$ include DVT, spasticity, severe trauma, pressure sores, complete spinal cord injury, urinary tract infection and vigorous physiotherapy. 1,5,7 Three subjects in the current series had spasticity. Studies by Bodley et al. ${ }^{9}$ and Cassar-Pullincino et al. ${ }^{10}$ suggested that microtraumatic lesions in the muscle induced by vigorous physiotherapy might be responsible for HO. Pressure sores also increase the risk for HO. ${ }^{1,7}$ Five of the seven subjects had pressure sores. DVT is a risk factor as well as a complication of HO. ${ }^{4,7}$ Interestingly in this series one patient with DVT later developed HO.

Treatment of $\mathrm{HO}$ includes indomethacin, disodium etidronate, radiation, physical therapy, surgery, verapamil $^{1}$ and warfarin. $4,5,11-14$ Once the process of bone formation is complete the response to treatment is poor. In the present series ROM improved in only two among the seven patients. Among three patients who received indomethacin, the ROM improved in one. Another patient who improved was treated with diclofenac sodium. The role of ROM exercises is controversial as it may increase the inflammation and accelerate bone formation. 5 Some authors recommend ROM to maintain the mobility of the joint and prevent ankylosis. ${ }^{1}$ The patients included in this study were treated with 'benign neglect'. Buschlbacher et al noted that the incidence of HO is significantly lower in SCI receiving Warfarin. ${ }^{12}$ It may be noted that one of our patients developed $\mathrm{HO}$ while on heparin.

$\mathrm{HO}$ is a significant cause of disability although its incidence in NTM is not known. A search of recent medical literature (including a Medline search for the last 5 years) did not reveal any reports of $\mathrm{HO}$ occurring as a complication of NTM. This report high-lights the occurrence of $\mathrm{HO}$ in NTM. The interval between the neurological deficits and $\mathrm{HO}$ was between 4 and 32 weeks. The clinical features and risk factors for $\mathrm{HO}$ were similar to those of SCI. The diagnosis of $\mathrm{HO}$ was often missed initially. Patients with NTM, especially those at high risk, should be screened for HO by clinical examination, ESR and SAP levels. All subjects with clinical signs and laboratory evidence suggestive of $\mathrm{HO}$ may be treated with indomethacin and rest. Confirmation of diagnosis with three phase bone scan is desirable. The awareness about HO in NTM may help in early detection and intervention thereby limiting the disability.

\section{References}

1 Buschlbacher R. Heterotopic ossification: A Review. Crit Revs Phys Rehabil Med 1992; 4: 199-213.

2 Taly AB et al. Medical problems in Neurological rehabilitation setting. Paper presented at $24^{\text {th }}$ Annual National Conference of Indian Association of Physical Medicine and Rehabilitation 1996; Hyderabad, India.

3 Ditunno Jr JF, Young W, Donovan WH, Creasey G. The international standards booklet for neurological and functiona classification of spinal cord injury. Paraplegia 1994; 34: 70-80.

4 Colachis SC, Clinchot DM, Venesy D. Neurovascular complications of heterotopic ossification following spinal cord injury. Paraplegia 1993; 31: $51-57$.

5 Garland DE. A clinical perspective on common forms of acquired heterotopic ossification. Clin Orthop 1991; 263: 13-29.

6 Snoecx M, De Muynck M, Van Laere M. Association between muscle trauma and heterotopic ossification in spinal cord injured patients. Reflections on causal relationships and diagnostic value of ultrasonography. Paraplegia 1995, 33: 464-468.

7 Bravo-Payno P et al. Incidence and risk factors in the appearance of heterotopic ossification in spinal cord injury. Paraplegia 1992; 30: $740-745$

8 Colachis SC, Clinchot DM. The association between deep venous thrombosis and heterotopic ossification in patients with acute traumatic spinal cord injury. Paraplegia 1993; 31: 507-512.

9 Bodley R, Jamous A, Short D. Ultrasound in early diagnosis of heterotopic ossification in patients with spinal injuries. Paraplegia 1993; 31: $500-506$.

10 Cassar-Pullincino VN et al. Sonographic diagnosis of heterotopic bone formation in spinal injury patients. Paraplegia 1993 31: $40-50$.

11 Biering-Sorensen F, Tondevold E. Indomethacin and disodium etidronate for prevention of recurrence of heterotopic ossification after surgical resection. Two case reports. Paraplegia 1993; 31: $513-515$

12 Buschbacher $\mathrm{R}$ et al. Warfarin in prevention of heterotopic ossification. Am J Phys Med Rehabil 1992; 71: 86-91.

13 Schaeffer MA, Sosner J. Heterotopic ossification: Treatment of established bone with radiation therapy. Arch Phys Med Rehabil 1995; 76: $284-286$.

14 Banovac K, Gonzalez F, Wade N, Bowker JJ. Intravenous disodium etidronate therapy in spinal cord injury patients with heterotopic ossification. Paraplegia 1993; 31: 660-666. 